\title{
EL SECTOR CINEMATOGRÁFICO EUROPEO. CRISIS ONTOLÓGICA Y ¿CRISIS ECONÓMICA?
}

\author{
José Juan Videla Rodríguez ${ }^{1}$ \\ videla@udc.es \\ Carmen Costa Sánchez ${ }^{2}$ \\ carmen.costa@udc.es \\ Universidade da Coruña
}

Facultade de Ciencias da Comunicación

Material original autorizado para su primera publicación en la revista académica REDMARKA. https://doi.org/10.17979/redma.2010.01.05.4718

\section{Resumen}

El sector cinematográfico constituye un área económica con unas características singulares, que en Europa ha recibido la protección y la ayuda de las autoridades públicas nacionales y europeas para su desarrollo. A su situación, se añade la complicada coyuntura económica de los últimos años, una etapa difícil para los ciudadanos, para los gobiernos y para las empresas que trabajan en el sector, lo que hace que nos preguntemos, ¿cómo está afectando la crisis económica actual a la cinematografía europea? Para dar respuesta a este interrogante, revisaremos las cifras clave de los mercados cinematográficos de España, Francia, Italia y Reino Unido en el período comprendido entre 2002 y 2009.

\footnotetext{
1 Doctor por la Universidade Complutense de Madrid. Desarrolla su labor investigadora y docente en la Facultad de Ciencias de la Comunicación de la Universidade da Coruña. Sus líneas de investigación se centran en la estructura del sector audiovisual, periodismo audiovisual y gestión comunicativa de crisis.

${ }^{2}$ Doctora por la Universidade de Santiago de Compostela. Desarrolla su labor investigadora y docente en la Facultad de Ciencias de la Comunicación de la Universidade da Coruña. Sus líneas de investigación abarcan la Comunicación para la Salud, la Comunicación Corporativa y la Estructura del Sistema Audiovisual. 


\title{
Palabras clave
}

Cine, producción cinematográfica, exhibición cinematográfica, Europa

\begin{abstract}
THE EUROPEAN MOVIE INDUSTRY. ONTOLOGIC CRISIS AND ECONOMIC CRISIS?

The movie industry constitutes an economic special sector, which in Europe also has received the protection and the help of the public national and European authorities. To its "special" situation, there is added the difficult economic conjuncture of the last years, a difficult stage for the citizens, for the governments and for the companies of the sector, which does that we wonder: how is affecting the crisis to the European movie industry? To give response to this question, we will check the key numbers of the movie markets of Spain, France, Italy and United Kingdom in the period between 2002 and 2009.
\end{abstract}

\section{Key words}

Movie industry, movie production, showing, Europe 


\section{INTRODUCCIÓN. ESPECIFICIDADES DEL SECTOR} CINEMATOGRÁFICO.

El estudio que presentamos ofrece un análisis de la evolución del sector de la producción y la exhibición en cuatro de los mercados cinematográficos de la Unión Europea (España, Francia, Italia y Reino Unido).

El periodo abarca de 2002 a 2009 , ocho años de una década en la cual las transformaciones en el cine afectan al modelo de negocio presente y futuro. Abordamos una industria que en Europa está fuertemente mediatizada por la competencia exterior y apoyada por políticas nacionales y trasnacionales que pretenden potenciar el mercado interno, pero que no han conseguido limitar la preponderancia de la industria cinematográfica norteamericana (Menor, 2006: $6)^{3}$. Es una industria global para la gran maquinaria de producción norteamericana, controlada por las grandes productoras norteamericanas, ahora integradas en gigantescas corporaciones multimedia. Una de las razones apuntadas al éxito de la producción norteamericana ha sido la diversidad cultural y étnica que los Estados Unidos presentan como país, lo que les ha permitido elaborar productos adecuados a audiencias bien diversas, factor que ha favorecido la exportación de dichos productos.

"Consequently, having taken into consideration the question of cultural discount during the production stage in order to distribute the film on the domestic market, American films, with their inclination to focus on the minimum common denominators of the diverse cultures, encounter fewer obstacles than others in international markets" (Cuco, 2010: 155-156).

"Su gigantesco mercado interior, su capacidad económica y de creación, y sus poderosas redes comerciales exteriores les han permitido dominar los mercados mundiales y expansionar su industria de películas sin un apoyo estatal declarado" (Cuevas, 1999: 53).

\footnotetext{
3 El contexto cinematográfico mundial se caracteriza por un dominio abrumador y prácticamente universal del cine de Hollywood, salpicado por una multitud de mercados nacionales autárquicos: las dos terceras partes de las películas producidas no salen de su país de origen (...). A pesar de Eurimages, del programa Media y de otras políticas activas, no existe, sin embargo, un espacio audiovisual europeo relevante, más allá de la existencia de ciertas zonas de permeabilidad lingüística (Suiza, Bélgica, Irlanda,...).
} 
La cinematografía es una actividad singular, en la que no rigen los principios que ordenan la fabricación y el comercio de otros bienes. Algunas características que singularizan al producto audiovisual frente a otros serían las siguientes (Pablo Martí y Muñoz Yebra, 2001: 125-126).

1. Permite ser transmitido y consumido, por lo que la aplicación de restricciones comerciales a este tipo de productos son cada vez más difíciles.

2. Muchos de los productos audiovisuales pueden comportarse parcialmente como bienes públicos lo que impide la aplicación de la regla de precio igual a coste marginal como criterio de eficiencia.

3. Las actividades audiovisuales entrañan un elevado grado de riesgo empresarial ya que cada producto es único e irrepetible al realizarse a partir de una combinación, también única, de factores productivos.

4. Puede ser duplicado a bajo costo, lo que alienta la piratería.

5. La posibilidad de que pueda ser utilizado indefinidamente dificulta su consumo y, por tanto, su control.

6. El cambio digital está permitiendo la generación de un sector multimedia que, en la medida que es digital permite su distribución internacional a través de canales de difícil control.

Al mismo tiempo, no estamos únicamente ante una actividad productiva, sino que nos situamos, tal como recoge la Ley del Cine en vigor, frente a un sector cuya acción tiene implicaciones económicas, culturales y hasta políticas. ${ }^{4}$

Buscando una traducción estrictamente empresarial, la especificidad de la actividad cinematográfica se puede resumir en los siguientes puntos:

- La producción nacional no cubre la demanda del mercado.

- Las producciones no se amortizan en el mercado nacional.

\footnotetext{
${ }^{4}$ La Ley 55/2007, de 28 de diciembre, del Cine, publicada en el Boletín Oficial del Estado de 29 de diciembre de 2007, indica en su exposición de motivos que el cine es "un sector estratégico de nuestra cultura y de nuestra economía (...). Su contribución al avance tecnológico, al desarrollo económico y a la creación de empleo, junto a su aportación al mantenimiento de la diversidad cultural, son elementos suficientes para que el Estado establezca las medidas necesarias para su fomento y promoción, y determine los sistemas más convenientes para la conservación del patrimonio cinematográfico y su difusión dentro y fuera de nuestras fronteras".
} 
- La película es un modelo que requiere una importante inversión de capital, tiempo y trabajo.

- Exige una alta inversión económica que se recupera lentamente por ser su consumo sucesivo.

- No hay relación directa entre el montante de la inversión y la calidad del resultado.

- No hay normas para fabricar una película de éxito comercial; la demanda varía en función de la calidad que aprecia el espectador.

La irrupción de las nuevas tecnologías digitales está provocando cambios en las estructuras cinematográficas. La introducción de los soportes digitales a lo largo del proceso de la película (rodaje, posproducción y exhibición) supone la orientación del cine hacia nuevas vías de negocio y expresivas.

La producción cinematográfica ha atravesado en los últimos cincuenta años etapas en las que se han alternado periodos de gran expansión con otros de decadencia; las fases de crecimiento de los últimos quince años se han basado en tres factores básicos:

- Incremento de los multicines en todo el mundo. Parte de las construcciones se deben a compañías productoras de películas.

- Desarrollo del mercado del vídeo doméstico y, posteriormente, del disco digital.

- El auge de la transmisión televisiva por distintos canales, que demanda productos.

Los cambios en la industria cinematográfica mundial han sido relevantes en los últimos años. Las fusiones y adquisiciones en el proceso multimedia han transformado el sector. Se tiende claramente a la concentración porque son necesarias estrategias globales de comercialización en los diferentes soportes para limitar los márgenes de incertidumbre de los productos cinematográficos.

Las formas de explotación de las películas se han modificado a causa del cable, el satélite y la digitalización en general. La exhibición en sala ya ha cedido peso frente al consumo individual a través de las televisiones de pago o 
abiertas, o difusión por Internet, en definitiva, "la cultura digital de consumos y dispositivos es la responsable de la extinción de los cines" (García Matilla; Arnanz, 2008: 121). Sin embargo, hemos asistido a un proceso en el cual se han multiplicado los complejos multisala, buscando una exhibición intensiva, con ocupación de espacios y pases por parte de las grandes productoras. Fue una estrategia para evitar la caída libre de espectadores, salas y recaudación (García Santamaría, 2009: 151).

Desde el punto de vista de la inversión en el sector, las televisiones, públicas y privadas, se han visto obligadas a invertir por ley una parte de sus beneficios en la producción cinematográfica.

El incremento de la demanda incide en el crecimiento de la producción y, por otra parte, potencia la realización de películas con grandes presupuestos, que consiguen más beneficios. Los grandes estudios se concentran en las películas comerciales y se tiende a homogeneizar el contenido y a arriesgarse poco. Los cines europeos han perdido cuota de mercado en beneficio del americano; se producen problemas estructurales (bajo presupuesto, mercados autárquicos y reducidos). El cine europeo sigue constreñido en los mercados nacionales, entre otras cosas por la diversidad cultural del continente.

En el marco del contexto descrito, tiene lugar en el año 2008 una crisis económica que ha sido comparada con la generada por el crack del 29. Dicha crisis ha afectado de manera global a países bien distintos, como los cuatro que configuran el análisis del presente estudio. La pregunta a la que pretendemos responder en el presente artículo es la siguiente: ¿Ha afectado la crisis económica en la que estamos inmersos al sector cinematográfico europeo? O más concretamente, ¿en qué magnitudes de los subsectores de la producción y la exhibición cinematográfica se ha percibido el impacto de la crisis económica?

\section{METODOLOGÍA EMPLEADA.}


El presente artículo estudia las principales magnitudes de los subsectores de la producción y la exhibición cinematográfica en cuatro países europeos: España, Italia, Francia y Reino Unido.

Hemos seleccionado el subsector de la producción cinematográfica porque es el que permite medir el esfuerzo económico interno y su materialización en un número determinado de obras cinematográficas que finalmente serán estrenadas. Hemos escogido asimismo el sector de la exhibición porque permite valorar cuantitativamente el efecto de la exhibición de esas obras por parte de los ciudadanos en términos de asistencia; por otra parte, ofrece la medida del retorno económico que los largometrajes estrenados han conseguido.

El objetivo principal era el de averiguar si la crisis económica general está afectando también al sector cinematográfico o si, dadas sus particularidades y especificidades, éste está respondiendo de manera positiva a diferencia de otros sectores económicos. Como ya se ha indicado, el periodo de estudio ha abarcado del 2002 al 2009, un periodo de ocho años, que nos dará las claves que podremos contrastar con un subperíodo de especial interés para el presente trabajo, el bienio $2008^{5}-2009$, cuando se produce la crisis económica en la que aún estamos inmersos.

En base a lo ya explicado, se han tomado como magnitudes de interés para el análisis, las siguientes:

\begin{tabular}{|c|c|}
\hline Subsector & Magnitudes analizadas \\
\hline \multirow{6}{*}{$\begin{array}{l}\text { Producción } \\
\text { cinematográfica }\end{array}$} & Número de largometrajes de capital nacional \\
\hline & Número de coproducciones de mayoría nacional \\
\hline & Número de coproducciones de mayoría extranjera \\
\hline & Coste medio por película \\
\hline & Inversión en filmes $100 \%$ nacionales \\
\hline & Inversión en filmes de iniciativa extranjera \\
\hline
\end{tabular}

\footnotetext{
${ }^{5}$ La caída del banco norteamericano Lehman Brothers en septiembre de 2008 es considerada la fecha de referencia en el inicio de la crisis económica actual.
}

REDMARKA UIMA-Universidad de A Coruña - CIECID

Año 2, Número 5, (2010), pp.103-128 


\begin{tabular}{|l|l|}
\hline Exhibición cinematográfica & Número de espectadores \\
\cline { 2 - 2 } & Ingresos en taquilla \\
\cline { 2 - 2 } & Cuota de mercado \\
\cline { 2 - 2 } & Número de pantallas digitales \\
\hline
\end{tabular}

Tabla $\mathrm{n}^{\circ}$ 1. Magnitudes analizadas en los subsectores de la producción y exhibición. Elaboración propia

Para la obtención de los datos se ha recurrido a fuentes primarias que son las fuentes reconocidas como oficiales en los mercados analizados y que, principalmente, son:

$\checkmark$ En España, el Ministerio de Cultura, a través del área de Cine y Audiovisuales.

$\checkmark$ En Francia, el Centre National du Cinéma et de l'Image Animée.

$\checkmark$ En Reino Unido, el United Kingdom Film Council.

$\checkmark$ En Italia, la Associazione Nazionale Industrie Cinematografiche Audiovisive.

Asimismo, también se ha recurrido a fuentes secundarias, como los informes del Observatorio Europeo del Audiovisual o los informes de las asociaciones profesionales del sector.

Puesto que se partía de fuentes de datos distintas, se ha llevado a cabo una etapa de definición de conceptos, de manera que las categorías de análisis empleadas no variasen en función de la terminología utilizada por los informes de los distintos organismos. Así, dentro del volumen global de largometrajes producidos hemos diferenciado los productos elaborados con capital enteramente nacional y las coproducciones con otros países, especificando la participación -mayoritaria, minoritaria y, en el caso español, equilibrada- del capital aportado por las productoras de cada estado.

Para la contabilización del número de películas nacionales producidas se han considerado como tal las financiadas por capital total del país en cuestión y las coproducidas con participación mayoritaria. Por lo que respecta a la información sobre el coste medio de cada película, hay estados con un volumen de datos superior a otros, como ocurre con España y Reino Unido, 
donde se presenta el coste de la participación española o el coste medio por película coproducida en el Reino Unido; este hecho es consecuencia del distinto nivel de información que proporcionan las administraciones u organismos competentes.

También en el cuadro británico se han recogido las cifras de las denominadas inward films, que son películas financiadas y controladas por productoras extranjeras pero que se realizan en ese estado atraídos por la infraestructura y/o incentivos fiscales del Reino Unido.

El concepto de número de espectadores que manejamos hace referencia al número de entradas vendidas. El concepto de cuota de mercado se refiere al número de películas exhibidas, no al número de espectadores ni de recaudación.

La categoría de pantallas digitales incluyen aquellas que han sido adaptadas para la exhibición cinematográfica en digital, en lugar de en $35 \mathrm{~mm}$. Abarca por tanto también las pantallas preparadas para la exhibición en tres dimensiones, aunque no se reduce exclusivamente a este tipo de películas.

\section{RESULTADOS OBTENIDOS.}

\subsection{Análisis de la producción cinematográfica}

En los próximos epígrafes vamos a analizar el volumen y el valor de la producción cinematográfica en los cuatro países que hemos tomado como referencia; el objetivo es obtener un cuadro general de la evolución de la industria cinematográfica continental en los años previos a la crisis y el comportamiento en los años iniciales de la mencionada coyuntura económica.

\subsection{1.- Evolución de la producción cinematográfica francesa}

La cinematografía francesa es la que ocupa el primer nivel en todas las magnitudes objeto de estudio; sólo España se aproxima, al final del periodo considerado, en el número de películas producidas. Según podemos apreciar, 
el sector cinematográfico galo está en un rango superior al resto de cinematografías analizadas, singularmente en la inversión total y en los costes de producción.

Los valores económicos franceses superan ampliamente a los del resto de los países, tanto en el inicio como al final de la secuencia histórica. En 2002, el coste medio de una película francesa alcanzaba los 4,4 millones de euros y en 2009 los 5,1 millones, cifras a las que ningún otro país se acercaba en esas fechas de referencia.

Igual sucede en las cifras de inversión en películas de iniciativa nacional, que oscilan entre los 644 millones de 2002 y los 852 de 2009, un incremento cercano al $30 \%$. Sólo se produce un descenso en el progresivo incremento entre los años 2005 y 2006, circunstancia que también se registra, aunque con cifras inferiores, en los sectores cinematográficos español y británico.

Los dos años iniciales de crisis económica afectan a la cinematografía francesa. Se aprecia un descenso en el número de películas nacionales producidas, en las coproducciones, en los costes y en las inversiones. Especialmente relevante es la caída en la inversión de filmes nacionales, desde los 1.174 millones de euros de 2008 a los 852 del año 2009.

El volumen de producción de las películas francesas o de capital francés mayoritario también registra un progresivo aumento del $40 \%$ entre las cifras de 2002 y las de 2009, incremento sólo superado por el sector cinematográfico español, como tendremos oportunidad de verificar.

\subsection{2.- Evolución de la producción cinematográfica italiana.}

El cine italiano se mueve en los niveles más modestos de los cuatro países de los que nos ocupamos en este trabajo. Sus cifras de producción, coste e inversión están en el rango inferior y, tomados desde una perspectiva global, ofrecen un panorama de estancamiento del sector, con especial relevancia en lo que atañe al coste medio por película y a la inversión, como aparece reflejado en los gráficos 3 y 4 que hemos elaborado. 
Italia inicia la secuencia histórica con una producción de 113 películas de capital nacional o coproducciones de mayoría italiana, que es prácticamente el mismo número que se registra en 2009, 114 según los datos facilitados por la Associazione Nazionale Industrie Cinematografiche. Hay un abrupto descenso en los dos últimos años de 29 largos, ya que en 2008 se contabilizan 143 producciones. En los años intermedios destacan el descenso de 2005 y el sobresaliente incremento de 2008 , con un aumento del $30 \%$ en la producción italiana con respecto al año anterior.

Por lo que respecta al coste medio, la industria cinematográfica italiana presenta las cifras más bajas en comparación con el resto de países que analizamos. En 2002 se contabiliza un gasto medio de 1,9 millones de euros por filme, y en 2009 2,3 millones. La inversión del sector en películas italianas presenta un incremento del $20 \%$ entre 2002 y 2009 , el más modesto de los tres estados en los que se incrementan estas partidas durante el período analizado. El mismo panorama, con cifras menores, se produce en el capítulo de películas de iniciativa extranjera, donde la inversión en el año final de la secuencia 2009, 77 millones de euros- es inferior a la que se registraba en 2002, 93 millones.

\subsection{3.- Evolución de la producción cinematográfica española.}

España refleja en términos globales un sostenido crecimiento de las magnitudes analizadas durante la última década. Es significativo que incluso en los dos años de crisis financiera y económica -2008 y 2009- el número de largos de capital español se incrementa, en un contexto de caída en el resto de cinematografías analizadas.

El sector comienza la secuencia histórica con una producción de 101 películas españolas o de coproducción mayoritariamente española, y acaba en 2009 con 154, lo que supone un incremento del 50\%; sólo registra descensos en los años 2003 y 2005, en este último caso muy ligero ya que se producen tres películas menos que en el año anterior.

Sin embargo, la coproducción sufre oscilaciones. Parte de los 57 filmes coproducidos en 2002 y finaliza con 51 películas coproducidas en 2009; por el 
medio nos encontramos con descensos bianuales -2003 y 2004- y recaídas en 2006 y 2008, aunque se produce un aumento de las coproducciones en el año de inicio de la actual coyuntura de crisis económica.

Desde el punto de vista de la inversión y el coste destacamos un dato muy significativo: el importante incremento de la inversión en películas españolas. Tomando como referencia el coste medio de una película española, se parte de una inversión de 184 millones de euros y se alcanza en 2009 los 432 millones de euros, lo que significa un aumento del $140 \%$.

El coste medio de las películas españolas evoluciona desde los 2,3 millones de euros de 2002 hasta los 3,2 de 2009, un ascenso del 40\% que sólo se ve interrumpido en los 2007 y 2008, donde se registran cifras inferiores a los años precedentes, que se recuperan sin embargo en 2009 , en plena crisis, cuando se alcanza costes de producción semejantes a 2006, con 3,2 millones de euros de corte medio.

Como ya hemos reflejado en el análisis de evolución del número de coproducciones, en lo que respecta al coste medio de la participación española también se producen altibajos en la secuencia histórica. El coste medio es de 3,3 millones de euros en 2002 y desciende hasta el 1,6 de 2009, una caída del $50 \%$ que sólo repuntó en 2004 y significativamente en 2008, con 2,8 millones de euros. En este apartado se carecen de datos de los años 2005 y 2006, no facilitados por el Instituto de Cinematografía y Artes Audiovisuales.

\subsection{4.- Evolución de la producción cinematográfica en el Reino}

\section{Unido.}

El Reino Unido ofrece una evolución global descendente en todos los apartados analizados, excepto en el número de películas nacionales producidas. En el caso británico es preciso resaltar una particularidad: el relevante peso económico de las películas financiadas y controlados por productores extranjeros pero que se realizan en el Reino Unido acogiéndose a las facilidades fiscales y de infraestructura que ofrece el sector; son las llamadas inward films, que adquieren la nacionalidad británica tras pasar un test cultural. En cifras, este subgrupo parte de una inversión de 904 millones de 
euros en 2003 y en 2009 registra 855, una cantidad menor pero tan significativa que no es igualada o superada por las películas nacionales o las coproducidas.

Al igual que sucede en el resto de países, el último año considerado se producen más largos que al inicio; en el caso británico se pasa de los 45 de 2003 a los 71 de 2009, registrándose en 2005 y 2007 los principales saltos ascendentes. Por el contrario, la coproducción, tanto de mayoría británica como de mayoría extranjera, refleja un acusado descenso, ya que 2003 se contabilizan 106 largos mientras que en 2009 sólo se producen en ambas modalidades 22 películas.

Los costes del sector cinematográfico en el Reino Unido también siguen una senda descendente. Las películas domésticas caen desde 3,5 millones de euros hasta 1,7 millones, prácticamente el $50 \%$, y el coste de las coproducciones oscila de los 4 millones de 2003 a los 2,9 de 2009. Sin embargo, el coste medio por inward film aumenta un $100 \%$ toda vez que se inicia el período con un coste medio de 14 millones de euros y se alcanza 2009 con 28 millones.

Finalmente, el sector cinematográfico británico es el único de los cuatro que invierte menos al final del periodo analizado, con un retroceso del $30 \%$. Las coproducciones también reflejan una evolución negativa ya que se produce un descenso del $83 \%$ en consonancia con la caída ya apuntada del número de coproducciones totales. Es menos acusada la disminución en las calificadas como inward film, un $6 \%$. 

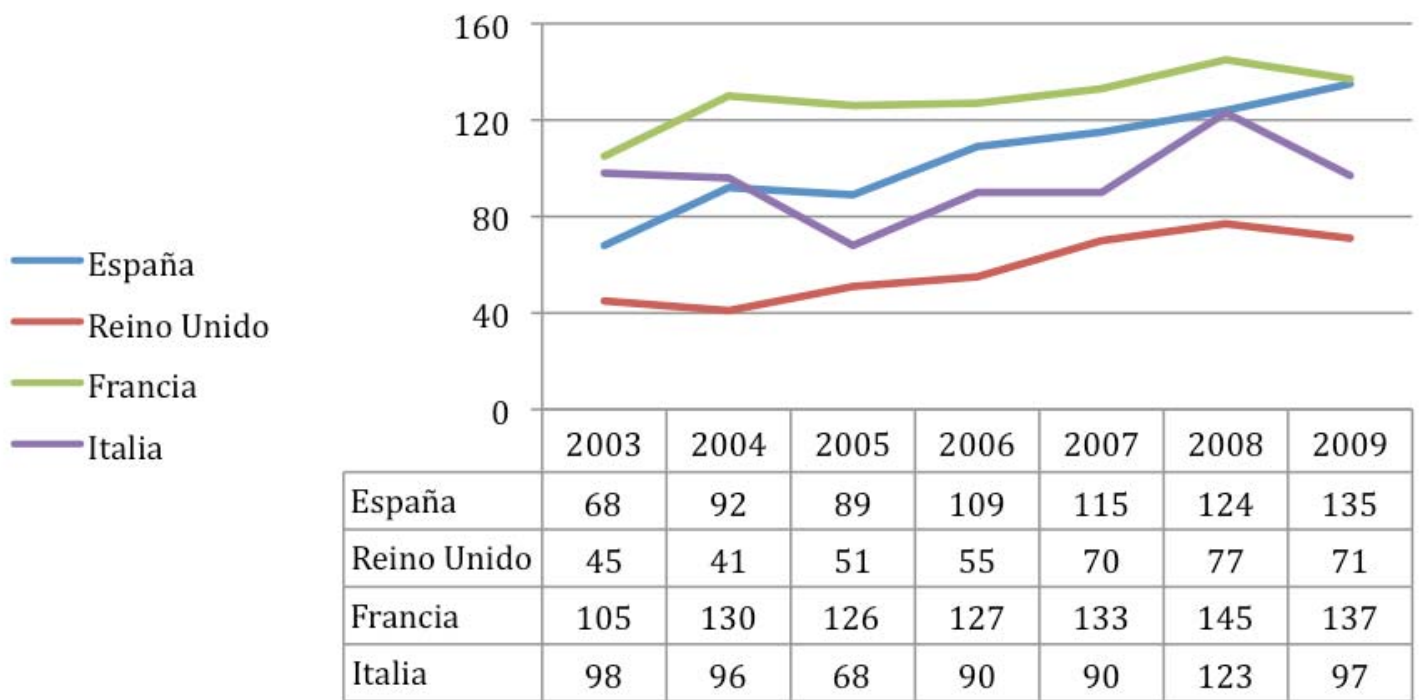

Gráfico n 1. Largometrajes producidos. Evolución (2002-2009). Elaboración propia.

\subsection{Análisis de la exhibición cinematográfica}

En este apartado analizaremos las magnitudes englobadas en el capítulo de exhibición para conocer si la crisis económica está afectando a este subsector de la industria cinematográfica europea.

\subsubsection{Espectadores/Entradas vendidas}

En cuanto al número de espectadores, podemos observar una evolución en el período 2002-2009 con semejanzas y diferencias en los países europeos analizados.

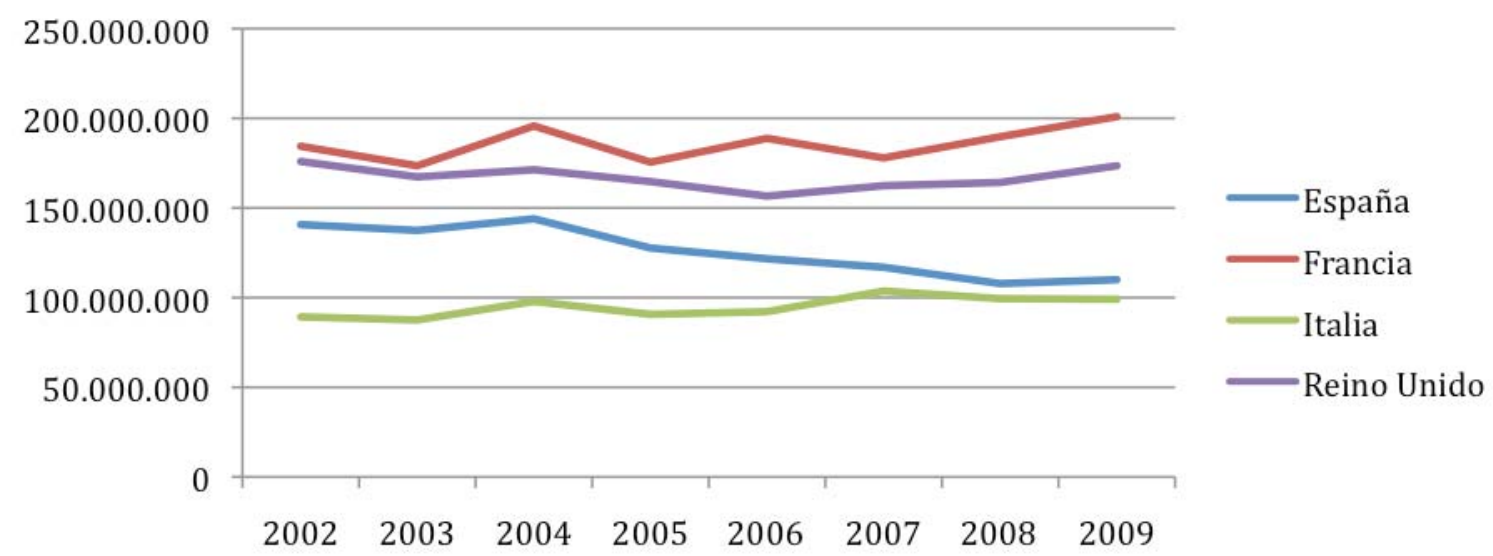

Gráfico n² 2. Entradas vendidas. Evolución (2002-2009). Evolución propia.

REDMARKA UIMA-Universidad de A Coruña - CIECID

Año 2, Número 5, (2010), pp.103-128 
De partida, Reino Unido y Francia son países que en 2002 figuran con una cifra de espectadores similar, en ambos casos superior a los 175 millones de entradas vendidas. Al final del período de análisis, en 2009, esa cifra mejora para Francia, pero empeora para el Reino Unido, que termina la década con diez millones menos de espectadores que en 2002.

El caso italiano y español, más distanciado de los otros países europeos, parte de una situación disímil, más favorable para España en cuota de espectadores, que sin embargo termina con una situación bastante parecida, lo que supone una caída de espectadores en el caso español y un incremento en el caso italiano. En concreto, Italia gana diez millones de espectadores en el período 2002-2009, mientras que España pierde 30 millones.

Tomando las cifras por países, observamos que:

En España, comienza un declive en el número de entradas vendidas a partir del año 2005, de manera que año tras años se van perdiendo espectadores. Otro pico descendente podemos encontrarlo en el año 2008, con unos 107 millones de espectadores, que sin embargo remonta en 2009 en unos dos millones de entradas vendidas.

En Italia, en 2005 hay un descenso en la evolución del número de entradas vendidas, que continúa a partir de ahí su progresión ascendente hasta que vuelven a bajar en 2008 continuando con un ligero descenso en 2009.

En Reino Unido, también 2005 y además 2006 son unos años de descenso abrupto en el número de entradas vendidas que, a partir de ahí, inician una remontada hasta el año 2009 inclusive.

En el caso de Francia, los años 2003, 2005 y 2007 son años de descenso en la asistencia a las salas, mientras que 2008 y 2009 son años de buenos resultados para el país galo.

En conclusión y como denominador común podemos apuntar el año 2005, como año de caída en el número de espectadores en los cuatro países europeos analizados. 
En el período considerado como clave para la crisis económica mundial, 20082009, de especial relevancia para este trabajo, encontramos una mejora en resultados, esto es, en número de entradas vendidas para los cuatro mercados cinematográficos objeto de estudio, excepto Italia, donde, no obstante la bajada no resulta significativa y casi podríamos hablar de un "estancamiento". Destaca, por positivo, el caso francés, donde desde 2007 se está produciendo un incremento considerable en el número de espectadores que acuden a las salas cinematográficas.

\subsubsection{Ingresos en taquilla}

Los cuatro países europeos han ido aumentando los ingresos en taquilla desde los inicios de la década, siendo España el país en el cual el incremento ha sido más bajo, de unos aproximadamente 50 millones de euros en siete años, lo que supone una media de 7 millones de euros por año.

\begin{tabular}{|l|l|l|l|}
\hline País & \multicolumn{1}{|c|}{$\begin{array}{c}\text { Recaudación en } \\
\mathbf{2 0 0 2}\end{array}$} & $\begin{array}{c}\text { Recaudación en } \\
\mathbf{2 0 0 9}\end{array}$ & \multicolumn{1}{c|}{ Diferencia } \\
\hline España & $625.904 .464,73$ & $671.043 .785,52$ & $+45.139 .320,79$ \\
\hline Francia & 1030.000 .000 & 1.232 .910 .000 & +202.910 .000 \\
\hline Reino Unido & $755.000 .000 £$ & $944.000 .000 £$ & $+189.000 .000 £$ \\
\hline Italia & 525.443 .490 & 623.479 .954 & +98.036 .464 \\
\hline
\end{tabular}

Tabla nº 2. Recaudación en 2002 y en 2009. Diferencia. Elaboración propia.

En España, cabe destacar el incremento que se produce en el año 2009 respecto a 2008 en los ingresos obtenidos en taquilla, el incremento más fuerte de su evolución junto con el experimentado en 2004 respecto a 2003. Por lo tanto, podríamos hablar de una recuperación económica del sector coincidiendo con la crisis económica global.

En Italia, el año 2005 supone un importante retroceso en los ingresos en taquilla. También debemos subrayar que a pesar del estancamiento del que 
hablábamos en el número de espectadores entre 2008-2009, hay un aumento de las cifras en taquilla en 2009 , lo que nos habla del incremento del precio de la entrada, experimentado también en parte gracias a la incorporación a las pantallas italianas de obras audiovisuales en $3 d$, cuyo coste para el espectador es superior.

En Reino Unido, no es en 2005 sino en 2006, cuando encontramos una bajada de las recaudaciones de los cines británicos. Antes de ese año y después del mismo, la recaudación ha ido progresivamente en aumento.

En el caso de Francia, los años 2003, 2005 y 2007 han sido los más negativos para la exhibición cinematográfica.

Observando con detenimiento el periodo considerado clave para el presente trabajo, es decir el binomio 2008-2009, comprobamos que en 2008 se produce un bajón respecto a los ingresos en comparación con el año 2007, sin embargo, en 2009, tiene lugar una recuperación de las recaudaciones en taquilla en los cuatro mercados europeos, que superan además las cifras de 2007. En este sentido, podemos concluir que la crisis económica mundial no ha afectado al sector cinematográfico europeo como cabía esperarse.

\subsubsection{Cuota de mercado}

En cuanto a la cuota de mercado estadounidense en los países analizados, debemos apuntar que en 2002, el país que tiene una mayor presencia del cine estadounidense en sus salas y pantallas es el Reino Unido (con un $73,4 \%$ ), seguido de Italia $(60,18)$, Francia $(49,9)$ y España $(39,2)$. El final del período se cierra en 2009 con un incremento para el país británico y el italiano, junto con un ligero descenso de la cuota de mercado estadounidense para España y Francia. 
En lo que respecta a la cuota de mercado nacional en 2002, España es la que parte con una cuota de mercado nacional más baja (un 18,6\%), seguida de Italia $(22,2 \%)$, Reino Unido (24,4\%), y finalmente Francia $(34,9 \%)$.

La cuota de mercado estadounidense en el mercado español no ha alcanzado a lo largo de este período el $40 \%$, aunque lo ha rozado en diversas ocasiones. Francia, por su parte, se ha mantenido siempre en niveles inferiores al $50 \%$.

El Reino Unido alcanza su mayor cuota de mercado nacional en 2005, complementada con una baja presencia de cine norteamericano, no obstante debemos hablar casi siempre de cuotas de mercado nacional inferiores al 30\%.

En el caso de Italia, podemos encontrar diferentes altibajos en la cuota de mercado propia que se complementan con otros tantos de la cuota norteamericana. En los dos últimos años, el binomio objeto de estudio 20082009, podemos detectar que en 2009 se incrementa en tres puntos la cuota de mercado norteamericana, mientras que la propia desciende en casi seis.

En general, en los años que corresponden a la crisis económica global (20082009), se produce un aumento de la presencia del cine norteamericano en los cuatros mercados europeos analizados, siendo el incremento más notable el acaecido en el Reino Unido. Por otra parte, la cuota de mercados nacionales desciende en Italia, Francia y especialmente en Reino Unido, mientras que en contraposición con esta tendencia general se incrementa ligeramente en España (en concreto en 0,7 puntos). 


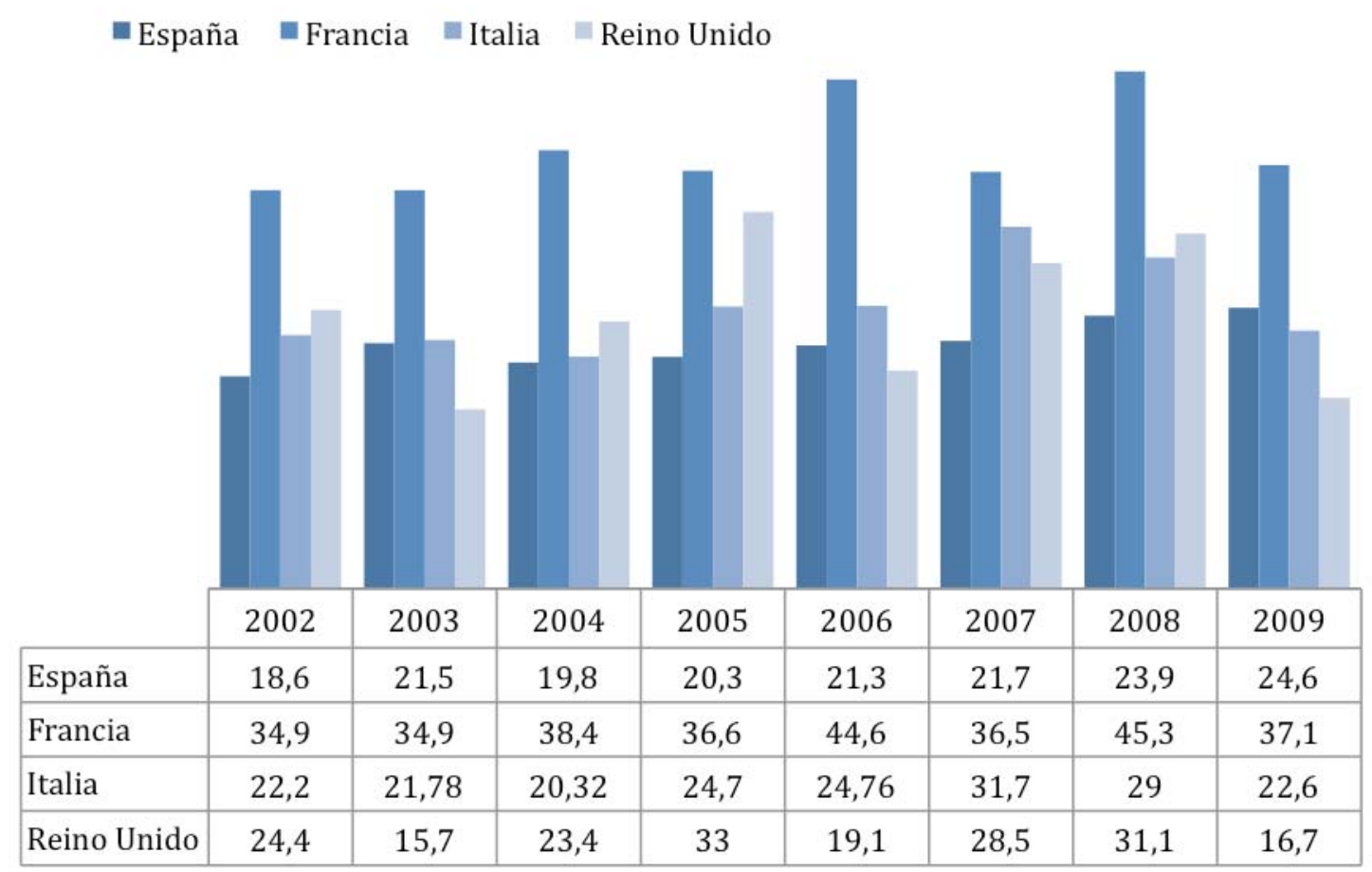

Gráfico n 3. Cuota de mercado de cine nacional. Evolución (2002-2009). Elaboración propia.

\subsubsection{Digitalización de las pantallas}

La eclosión de las pantallas digitales se produce en todos los países analizados entre el 2007 y el 2009, siendo el incremento más significativo en el bienio objeto de reflexión en el presente artículo. Es España el país que, según los datos aportados, posee un menor número de pantallas digitales, mientras que Francia ofrece el contrapunto con 930 pantallas en 2009.

El Reino Unido ofrece un crecimiento más sostenido desde 2005, mientras que los restantes países analizados realizan una apuesta decisiva por la digitalización del sector de la exhibición desde 2007 y sobre todo desde 2008. 


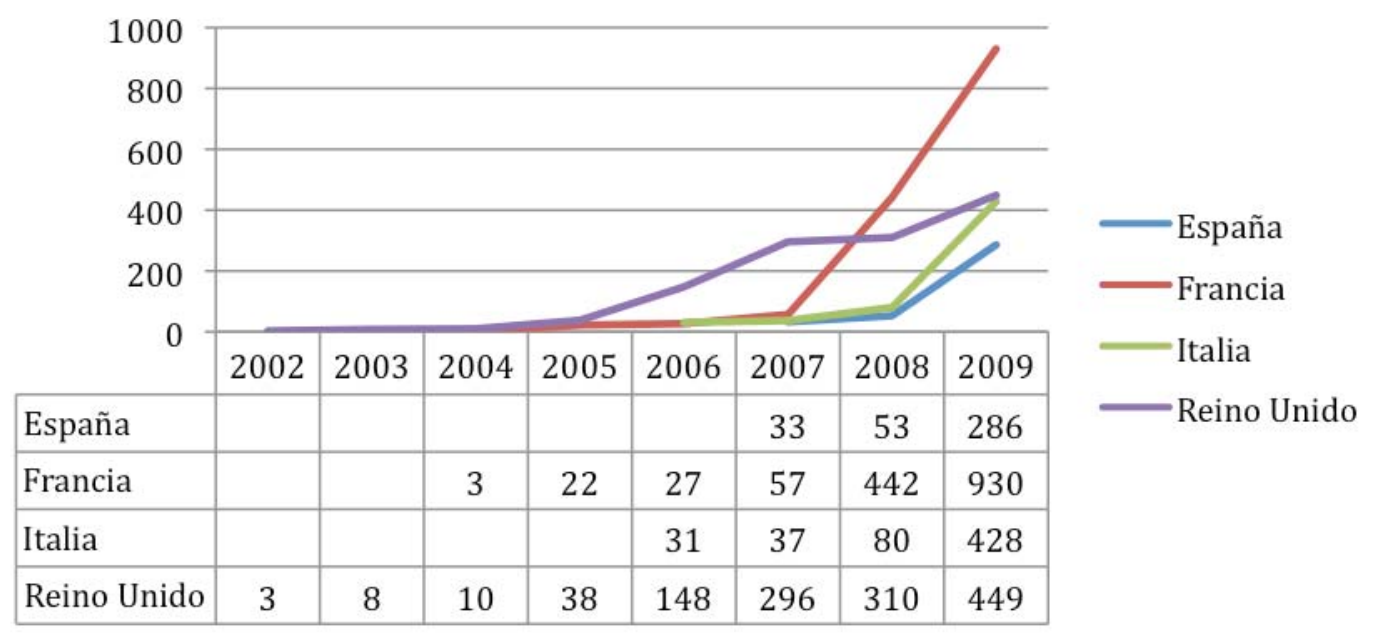

Gráfico $n^{\circ} 4$. Pantallas digitalizadas. Evolución (2002-2009). Elaboración propia. 


\section{CONCLUSIONES. IMPACTO DE LA CRISIS ECONÓMICA EN EL SECTOR CINEMATOGRÁFICO.}

En un análisis global de las magnitudes de producción analizadas en el periodo 2002-2009 concluimos que el cine europeo mantiene un proceso de crecimiento moderado. Sólo el Reino Unido muestra una línea opuesta, con caídas apreciables en diversos apartados. En las magnitudes de exhibición, nos encontramos un paisaje irregular en el que las caídas más importantes en número de espectadores se producen en el período 2005-2007.

En el periodo comprendido entre los años 2008 y 2009 -coincidente con los años de crisis económica- hay una mayoría de países que reflejan un descenso moderado en volumen de producción y valor económico (inversión y coste). Sólo en Francia cabe anotar fuertes caídas en coste medio e inversión del sector.

La crisis no afecta, no obstante, al número de espectadores de las salas europeas que se recupera o mantiene respecto a los datos correspondientes a 2007. En cuanto a la recaudación obtenida en taquilla, los datos de 2008 son peores que los de 2007 para España e Italia, mientras que los ingresos aumentaron para Reino Unido y Francia. No obstante, 2009 ha permitido mejorar las cifras de 2007 en todos los mercados estudiados.

Si nos detenemos en la cuota de mercado de cine nacional en las pantallas europeas, nos encontramos con que el año 2009 ha castigado más fuertemente a Reino Unido y a Francia, que a lo largo del periodo de estudio ha destacado por sus elevadas cuotas de mercado nacional, mientras que España, gracias a los éxitos nacionales del 2009 (Celda 211, Ágora, Rec 2, Planet $51 . .$. ) consigue salvar una buena posición. 
En cuanto a la digitalización de las pantallas, su despegue ha sido imparable, aún coincidiendo con los años de crisis económica. En definitiva, el presente estudio nos ha permitido concluir que:

- La crisis económica global, que está afectando a la economía de Estados Unidos y de Europa, está produciendo efectos moderados en el sector cinematográfico, que desde luego no afectan a la asistencia de público a las salas.

Dicha conclusión permitiría dar por válida la hipótesis del cine como evasión, según la cual la gente acude al cine para evadirse de los problemas de la vida cotidiana que, en contexto de crisis económica, se verían agudizados.

Habrá que observar cómo evolucionan los datos de asistencia a las salas en los próximos años, así como el proceso de crisis económica, para comprobar si existe un punto de inflexión en este sentido.

- La crisis económica ha perjudicado los ingresos en taquilla en 2008, pero no en 2009, cuando se mejoran las cifras obtenidas en 2007 . Este dato se encuentra en relación tanto con el incremento del número de espectadores como con la subida del precio de la entrada, que además de sufrir el incremento relativo al IPC, sube su precio cuando se trata de filmes en 3D.

La digitalización de las pantallas de exhibición tiene un importante peso en este sentido, proceso que se ha visto acelerado en los años 2008-2009, aunque España tiene bastante camino que recorrer en comparación con otros países europeos.

"Various elements have contributed to this acceleration of the digitisation process: the designation of the $\mathrm{DCl}$ format as the international standard, the development and propagation of the Virtual Print Fee (VPF) model by which distributors contribute, through thirdparty investors, to financing the digitisation of cinemas, and the arrival of 3D, which finally provided exhibitors with a commercial argument by offering the public a new cinema experience" (Lange, 2010: 7). 
- Una de las principales consecuencias de la crisis económica en el cine ha sido la reducción de los filmes de producción propia en el año 2009 (con la única excepción de España, país en el que durante los años 2008 y 2009 , el número de largos de capital español crece casi un $10 \%$, en un contexto de caída en el resto de cinematografías analizadas). Dicho descenso se ha visto correspondido con el aumento de las coproducciones de mayoría extranjera y el descenso de las coproducciones de mayoría nacional. El descenso más pronunciado es el del Reino Unido, con una caída del 80\% entre 2003 y 2009.

Por lo tanto, podríamos concluir que la crisis económica ha promovido las coproducciones de mayoría extranjera porque los recursos nacionales se vuelven insuficientes para mantener la media habitual de largometrajes por año.

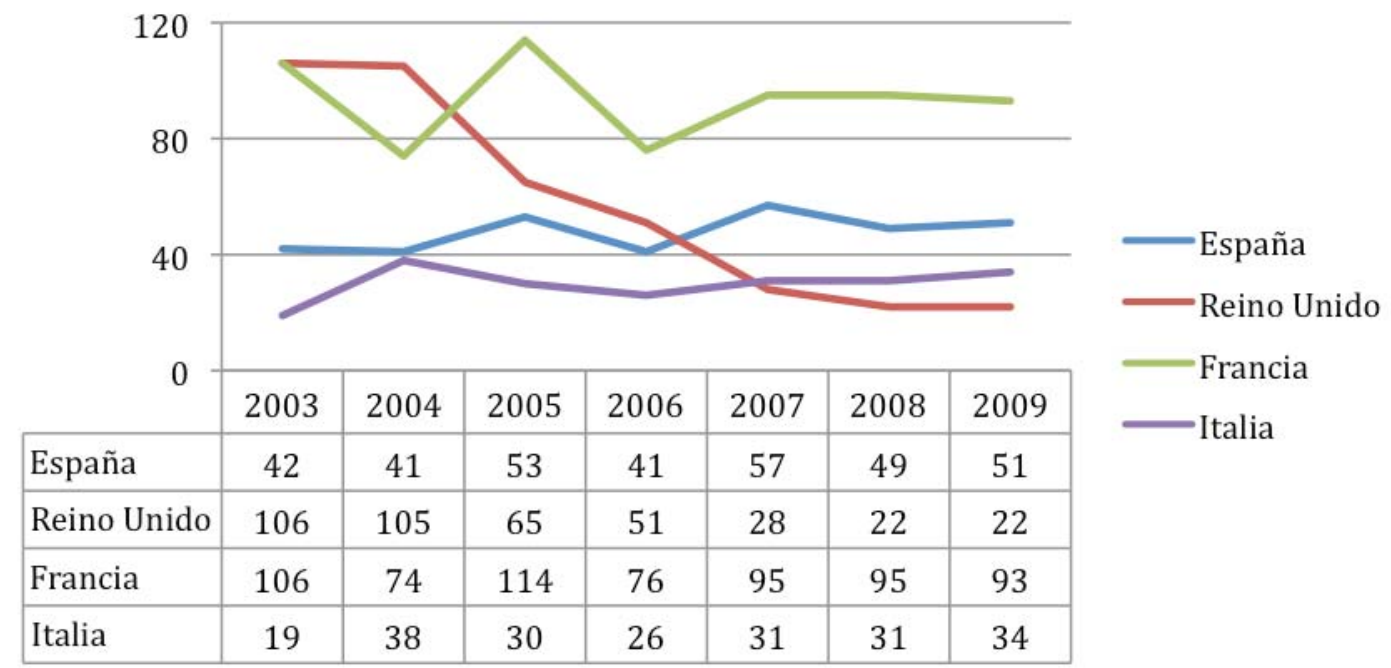

Gráfico n 5. Total de coproducciones. Evolución (2002-2009). Elaboración propia.

- Otra de dichas consecuencias negativas se ha producido en el coste medio por película, es decir, ha pasado a gastarse menos capital en la producción de los largometrajes. El sector de la producción cinematográfica francesa tiene un coste medio por película superior al resto, aunque entre los años 2008 y 2009 se registra un notable 
descenso. España incrementa el coste de sus películas e Italia también, aunque en menor cuantía. El Reino Unido va recortando progresivamente, especialmente entre los años 2005 y 2007, el coste medio de las películas nacionales; sin embargo, los filmes inward doblan su coste entre 2003 y 2009.

Por lo tanto la crisis económica está afectando negativamente, sobre todo, a magnitudes del subsector de la producción cinematográfica, mientras que el subsector de la exhibición está aguantando mejor la coyuntura económica actual. Se producen menos películas porque también se reducen las ayudas estatales a la producción cinematográfica en un sector de alto riesgo e intensamente dependiente.

"Este elevado riesgo dificulta de forma decisiva la financiación de este tipo de actividades, especialmente de las más innovadoras y arriesgadas desde el punto de vista cultural, por lo que en muchos países se ha realizado desde el ámbito público, ya sea mediante el establecimiento de ayudas y subvenciones a la producción audiovisual privada o, directamente, mediante la producción pública" (Pablo Martí y Muñoz Yebra, 2001: 125).

"El cine europeo no puede existir sin ayudas públicas, criterio compartido, como hemos visto, por todos los estados europeos y la Unión Europea. Sin embargo, las ayudas públicas deben tener en cuenta el cambio digital y adoptar un nuevo modelo" (Otero Timón, 2009: 219)

Así, en un contexto de debilidad económica de las autoridades públicas, se reafirma la presencia de cine estadounidense, que incrementa su cuota de pantalla, frente a la de cine nacional en las pantallas de los mercados europeos analizados.

Es necesario seguir de cerca la evolución de la crisis económica y de los datos del sector cinematográfico en 2010 para confirmar las tendencias y conclusiones hasta ahora apuntadas. Sería de interés comprobar si la hipótesis del cine como evasión que pudimos corroborar en este trabajo pasa a contradecirse en caso de condiciones económicas adversas pero también 
prolongadas, de manera que dichas circunstancias con continuidad en el tiempo acabasen afectando negativamente al consumo de las salas de cine.

Por otra parte, también sería de interés comprobar si el proceso de digitalización de salas y pantallas se frena o retrocede en el marco económico imperante o si, a pesar del descenso en la inversión, logra ganarse no sólo en la técnica sino también en la calidad de los largometrajes producidos en Europa.

\section{BIBLIOGRAFIA Y FUENTES CONSULTADAS}

Associazione Nazionale Industrie Cinematografiche Audiovisive e Multimediali. Área de Richerche e studi.

http://www.anica.it/dati\%20cinema/ricerche\%20e\%20studi.htm

Centre National de l'Animation et de l'Image Animée. Área de publicaciones.

Disponible en:

\section{http://www.cnc.fr/Site/Template/F4.aspx?SELECTID=593\&id=326\&t=3}

Cuco, M.

(2010). The boarders of the domestic market and their importance for the economy of the film industry: The Swiss case study", en European Journal of Communication, 25(2), pp. 153-167.

(2009): "The promise is great: the blockbuster and the Hollywood economy", en Media Culture Society, 31(2), pp. 215-230.

Cuevas, A. (1999): La economía cinematográfica. La producción y el comercio de películas, Madrid, Ed. Imaginógrafo.

García Matilla, E. Arnanz, Carlos M. (2008): El mercado de medios audiovisuales en España: la incertidumbre del cambio". Telos, vol. 75, p. 121.

García Santamaría, Jose V. (2009): "La transformación de los complejos de cine en complejos de ocio". Telos, vol. 78, p. 151.

Lange, A. (2010): “Saving Na'vi cinemas", en European Audiovisual Observatory: Focus 2010. World Film Market Trends, EAO.

Menor, Juan Jesús (2006): “El cine español ante la globalización”. Telos, vol. 66 , p. 6. 
Ministerio de Cultura: El cine y el vídeo en datos y cifras. Disponible en:

http://www.mcu.es/cine/MC/CDC/index.html

Otero Timón, J. M. (2009): ¿Por qué se ayuda al cine? Protección, arte y humor, Arganda del Rey (Madrid), Laxes Ed.

Pablo Martí, F. y Muñoz Yebra, C. (2001): "Economía del cine y del sector audiovisual en España”, en Economía de la cultura, n 792, pps. 124138.

United Kingdom Film Council.

Statistical Yearbook 2010, 2009, 2008. Disponibles en:

http://www.ukfilmcouncil.org.uk/article/16894/Statistical-Yearbook

Para citar este artículo:

Videla Rodríguez, José Juan - Costa Sánchez, Carmen (21-12-2010). EL SECTOR

CINEMATOGRÁFICO EUROPEO. CRISIS ONTOLÓGICA Y ¿CRISIS ECONÓMICA?.

REDMARKA - CIECID - Unidad de Investigaci $\tilde{A}^{3} n$ en Marketing Aplicado-Universidad de A CoruÃ $\pm a$

Año II, Número 5, V21-12-2010, pp. 130-128

ISSN 1852-2300

URL del Documento : cienciared.com.ar/ra/doc.php?n=1418

URL de la Revista : cienciared.com.ar/ra/revista.php?wid=39 